\title{
Research and Application of Work-Process-Oriented Project Clusters Teaching Model
}

\author{
Wenling $\mathrm{Gao}^{1, \text { a }}$ \\ ${ }^{1}$ Xi'an International University, Xi'an Shaanxi, 710077 \\ ${ }^{a}$ email
}

Keywords: The Work Process-Oriented; Projects; Cluster; Teaching Model; Application

\begin{abstract}
At present, China's vocational education theory and practice remains disengaged, teaching content does not match with the actual working conditions and other issues. With the research and application of work-process-oriented project teaching mode cluster deepening class situation of vocational education will be effectively mitigated. This article focuses on the work process-oriented project clusters teaching model, provide some useful suggestions for its application method.
\end{abstract}

\section{Introduction}

The fundamental purpose of higher vocational education is to meet the social demands of high-quality skilled personnel, is the organic combination of theory and practice, students can better adapt to society to adapt to work, to show self-worth. Therefore, higher vocational education should be career-oriented, the establishment of teaching mode has a distinct occupational attributes. Work-process-oriented teaching model cluster project is a new teaching mode, which breaks the traditional situation of vocational education in theory and practice is inconsistent, the effective promotion of vocational education in its essential purpose.

\section{Contents Work-Oriented Cluster of Projects Teaching Model}

A cluster is a computer system, is through software or hardware in a particular way to connect multiple computers together to complete the mission objectives [1]. The most significant advantages of the project can make full use of cluster utilization of the resources used to produce a cluster effect. Work-process-oriented cluster of projects, mainly through vocational teaching model ability to link related items set up so as to form a complete system, powerful Course. The core purpose of the model is effective personnel training, according to the student's specific career fields are learning to design-related learning software projects, and in accordance with the law of development of the profession will be independent of software projects grouped into a cluster of projects. Upon completion of a student and a cluster project is the gradual completion of the development of the profession, and ultimately master the theoretical knowledge and practical work consistent, enhance their professionalism, to become highly qualified skilled personnel.

\section{Advantage of Work-Process-Oriented Project Clusters Teaching Model}

Vocational education in the traditional teaching in the completion of the theoretical teaching on the then practice, such a teaching approach has a certain lag, it is easy and practical working environment and occupational demand generated out of line, which can not be realized simply Vocational Education purpose. Work-process-oriented project teaching cluster model is more emphasis on project work in the status of teaching, teaching plans, their contents are in accordance with the requirements of the work process is designed, it can be a very good combination of theory and practice, better students job skills and professionalism. In general, the teaching model has the following two advantages:

Traditional curriculum is static, closed, even if all of the courses are in accordance with a scientific approach to arrange, but still can not form between the system design of the project, can 
not achieve a good mastery of knowledge points. The work process-oriented project teaching mode cluster established curriculum is a dynamic, open learning system, not only the professional course in accordance with process knowledge and practical work tasks the way redesign also incorporates a plurality of related courses, so that students master the project through a variety of knowledge and skills needed to master.

The traditional teaching process is to master theoretical knowledge, during practice, to complete the task. This is the middle there is a certain lag, many students in practicing or completing tasks often find themselves forgotten or theoretical knowledge or possession of theoretical knowledge simply can not meet their needs. So, inevitably affect the quality and efficiency of task completion. Work-process-oriented project clusters teaching model theoretical knowledge and working time together organically, so that the combination of theory and practice has always been to ensure that students at the completion of the tasks have mastered the required knowledge.

Traditional teaching methods require students to customize largely involved in theoretical study and practice, if students do not play enough motivation will fall into a more passive state. In the teaching mode project cluster is a student project participants and implementers. Students must complete the task in order to learn to master the necessary theoretical knowledge to complete the task, so is bound to change students' attitude towards learning, improve student learning initiative. In this mode, the working process is always oriented so that students can be more profound understanding of the theory of knowledge, theoretical knowledge better digest and utilize.

A project is usually done by a team, is the need for joint student learning and discussion. Traditional mode of education, the teacher is teaching, although the leader, is also the subject of teaching. Teachers learn to master the content and progress, to some extent limit the development of students' self-exploration and self-learning ability. Cluster project teaching mode by way of the project reflects the dominant position of students in teaching, strengthen the guiding status of teachers, so that students have more space to be able to learn from each other, mutual discussion. In small groups to complete a project, students will be more collective sense of honor, in order to better enhance their teamwork. In the completion of the project at the same time, students can theoretical knowledge better, more systematic study and master.

\section{The Application Mode of Work Process-Oriented Project Teaching Mode Cluster Specific}

Even in the same profession, which also has a number of different jobs, and vocational skills and qualities needed for each job it is different each. Therefore, in developing work-process-oriented teaching model cluster project, to learn more about "the working process." Of professional positions to conduct a comprehensive study and analysis, ultimately determine the professional competence of training direction and objectives in order to develop in line with the actual needs of the project cluster job teaching courses such as IT enterprise software development needs JAVA programmer, net programmers, database open engineers, web production and client script writers and other professional positions [2]. Course designers should first conduct a comprehensive understanding of these positions, determine the positions of the standards of practice, skill requirements, designed to meet the needs of the current work programs. Key project cluster curriculum focuses on computer software to enhance students 'basic knowledge and mastery of basic skills, enhance students' ability to analyze, develop, design, innovation and application of the software.

In the design of the project should also maximize compliance with the current industry. Cluster project teaching mode task is to complete the work of a professional activity, which is required to complete the project contains a variety of practical tasks of the job, not the completion of a single task or a project can work. So in the design of the project, designers must not only learn more about the actual work tasks in various positions, but also from the software company and experts conducted seminar program content, design typical tasks in the project to meet learning standards and practice standards consistent.

After confirming the contents of a good project, you can summarize the students need to learn the range. A professional is composed of multiple fields of study composed of a plurality of fields of study is to learn from the situation composition [3]. Cluster instructional design project must go 
through specialized seminars and brainstorming, the students divided into learning the actual range of the most consistent. So that students feel deeply their knowledge of learning theory is useful and true, and learning is very necessary. Each design can be applied to the learning points in the sub-project, the completion of the project design but also to build a complete learning system.

When designing teaching scenarios or subprojects, designers should pay attention to be focused study, showing a specific teaching project. In the software development process, and always adhere to the "outstanding project subject to complete project tasks, project design necessary role, building an effective complete environment" principle. Upon completion of the project so students always have a kind of realism A true master their own knowledge to complete realistic tasks. Project designers can collect a variety of ways to the project, or create a special library project, the project for the establishment of cluster teaching mode with a solid foundation. Schools should increase cooperation with software companies, to implement a proactive mode that provides good data and authenticity, so that the model has more practical significance. The IT strategy and business development talent organic standards require integration projects, it is the core of the project design work, but it is difficult. Only by adhering to inspire students to follow the recognized professional knowledge and skills formation law, from easy to difficult, from shallow and deep, from the local to the whole, from the individual to the comprehensive principle, achieve mutual transformation enterprise projects and teaching programs.

In a process-oriented project work cluster teaching mode, the core is a work-oriented education is the main project of the cluster model, the condition is to establish a good platform for online teaching and self-learning, and the results of the project report [4]. Upon completion of the course the student project, you need to go through to collect messages, planning, implementation plans, the completion of inspection and assessment of completion of project results and other processes. Throughout the process, the students themselves or by the gradual completion of the team's strength to gather information, process information, application information, and several steps have been completed and the study and practice of knowledge unconsciously in this series of steps is high school students, mastered the necessary vocational skills. And according to the practice of handling problems in the process, we have a choice of learning objectives related to knowledge, self-improvement to achieve professional quality purposes. In the completion of the project to complete the process, teachers only need to be timely coaching and guidance, and do not give too much advice.

The completion of a project must involve many aspects of professional knowledge, classroom learning time is limited, not to enable students to complete learning-related knowledge. Establish an online learning platform, students' can communicate with each other, independent of completion of the required expertise. So will extend from the classroom to extracurricular learning, provide students with a better learning conditions. Seven modules online learning platform build by learning, inquiry began, evaluate, screen, communication and management background and other components, the use of textbooks and teaching materials used in teaching project is the same, in order to ensure that students can better understand and the use of different expertise [5]. The online learning platform related information and technology to provide students with the project to be completed in time, but also enhance the students' self-learning ability.

The outcome of the project is to allow students to report better understanding of the situation of their own to complete the project. Schools can be organized once each semester, in the form of class completion by the teacher detailed evaluation of each student to complete, particularly pointed out in the student's strengths and weaknesses, and to reward outstanding students and encourage, enhance students' confidence in learning, so as to better promote the teaching effect.

\section{Conclusion}

Core work process-oriented teaching mode cluster project is to develop high-quality skilled personnel, give full play to the dominant position of students in teaching, to stimulate students' independent learning ability and motivation of a teaching mode. This mode of organic combination of theory and practice together, students, schools, businesses linked together, so that students can 
better understand the content of his own profession, a better grasp of technology and quality of future job needs.

\section{Acknowledgements}

Pro: The pilot study of teaching mode based on the working process of the project-clustered in the professional transition, Field Project, Project Number: 2015B29.

\section{References}

[1] Li Dongxia. Based Research And Practice Working Process-Oriented Teaching Mode - Taking Our Financial Major "Computer Application Foundation" Courses As An Example [J]. Oriental Culture, 2014, 03: $340+343$.

[2] Wang Xie. Process-Oriented Teaching Mode In Vocational Professional Teaching [J]. Career Horizon, 2014, 03: 99-100 + 106.

[3] Zhang Di, Shen Yongkang, Liu Jie. Context-Based Modular Training Model of The Working Process [J]. Educational Research, 2010, 11: 96-98.

[4] Du Mingming. Work Process-Oriented Task-Based Approach [J]. New Curriculum Study (In Xunkan), 2011, 09: 93 -95.

[5] Feng Wei. Explore Based On Quality Teaching Mode Process [J]. Science and Technology Innovation Herald, 2010, 03: 237. 